\title{
VENTRICULAR MECHANICS AND INTRACARDIAC ELECTRO- GRAM IN EXPERIMENTAL BUNDLE-BRANCH BLOCK
}

\author{
BY \\ G. FOLLI, E. VITOLO, G. G. BATTIONI, AND G. P. ZOCCHE \\ From the Istituto di Patologia Speciale Medica e Metodologia Clinica of the University of Milano, Italy \\ (Director: Prof. Guido Melli) \\ Received March 3, 1959
}

Among the many unsolved problems in bundle-branch block, the question of the modification of the mechanical systole and the relationship between mechanical and electrical systole resulting from experimental interruption of the left or right branch of the bundle of His has aroused special interest.

This problem was considered in 1911 by Eppinger and Rothberger who described the electrocardiographic pattern of the bundle-branch block for the first time. These authors claimed that bundle-branch block causes asynchrony of the ventricular systole by retarding the contraction of the ventricle whose branch is damaged, but in numerous subsequent studies opinions on this question are still divided. Whereas Katz et al. (1935) and Braun-Mendenez and Solari (1939) have maintained that it is possible to have an intraventricular block without appreciable asynchronism between the two ventricles, Samet et al. (1950) have obtained opposing results, and other authors (Katz, 1925; Groedel, 1944; Chamberlein et al., 1947; Richards et al., 1947; Ellinger et al., 1948; Coblentz et al., 1949; Segers and Hendrick, 1951; Gigli and Muiesan, 1956; Gray, 1956) have observed various degrees of delay between the mechanical systole of the blocked ventricle and the mechanical systole of the other ventricle. Such studies are for the most part clinical and are necessarily based on methods (simultaneous recording of electrocardography, phonocardiography, cardiography, arterial sphygmography, and roentgenkymography of the great vessels) by which the beginning of the isometric systole of the two ventricles is not recorded and the beginning of isotonic systole or other phases of the cardiac cycle is indicated only indirectly.

Recently Braunwald and Morrow (1957), by means of catheterization of both ventricles, determined the relationship between the ventricular contractions in patients with right and left bundlebranch block. They observed that only in some of the cases was the beginning of the contraction of the blocked ventricle delayed.

In evaluating the results of the research carried out by these various authors it must be remembered first that the existence of an electrocardiographic picture of left or right branch block does not necessarily indicate the existence of an anatomical interruption of the branch at the bundle of His (Segers, 1949; Lasser et al., 1951; Alzamora-Castro et al., 1953; Donoso et al., 1955; Braunwald et al., 1956). Further, since the duration of the isometric systole in the two ventricles can vary even in physiological conditions (Samet et al., 1950), it is impossible to calculate the time of the beginning of the ventricular contraction from the beginning of isotonic systole. Moreover, an asynchronism in the closing of the semilunar valve is often present in cases in which there is no asynchronism in the beginning of the ventricular contraction (Braunwald and Morrow, 1957). Finally there may be myocardial lesions, valvular defects, or abnormalities in the pressure gradients in the different parts of the cardiovascular system-conditions often observed in patients with bundle-branch block-any of which may interfere, producing disorders of conduction and affecting 463 
the time of appearance and duration of the different phases of the cardiac cycle (isotonic systole, isometric systole, ventricular ejection, or closure of the semilunar valves).

Our first object in the experiments described in this paper was to study this problem by recording simultaneously intracardiac pressures and electrograms in both ventricles before and after left and right bundle-branch block. Our second object was to compare the intracardiac electrograms recorded simultaneously in the two ventricles. This, which, as far as we know, has never been done before enables one to compare the entire process of depolarization in the two ventricles. This approach was suggested by the work of Kennamer and Prinzmetal (1954) and Sodi-Pallares et al. (1955), who observed that the præcordial and epicardiac leads do not record potentials generated in the interior two-thirds of the ventricular wall. Intracardiac electrocardiography, furthermore, enables one to record local low voltage potentials that would not be detected by peripheral leads.

This study also contains a histological examination of the interatrial and interventricular septum in two hearts in which the left branch of the bundle of His has been resected.

\section{MATERIAL AND MeTHODS}

The experiments were carried out on 33 medium- and large-sized adult dogs of both sexes. Right bundlebranch block was produced in 18, and left bundle-branch block in 15 of these. All the experiments were carried out under general anæsthesia. Two catheters were placed in each ventricle; the right ventricle catheters were introduced through the two external jugular veins and the left ventricle catheters through a common carotid artery and a femoral artery. The catheterization was carried out under radioscopic control.

The first of each pair of catheters was an ordinary Cournand catheter, kept open with a continuous heparinized saline drip and connected to a Sanborn electromanometer for the recording of intracardiac pressures. At the distal end of the other catheter there was a silver electrode connected, by means of a metal wire inside the lumen, to a præcordial lead of an electrocardiogram. In this way the electrograms in each ventricular cavity were recorded.

Electrocardiograms and pressure tracings were recorded on a Twin-Viso Sanborn machine with a paper speed of $100 \mathrm{~mm}$./sec.

The position of the four catheters was checked, not only on the fluoroscopic screen, but also by the shape of the cardiograms and pressure tracings. Care was taken to avoid extrasystoles due to mechanical stimulation of the ventricular walls.

Initially and after production of bundle-branch block the following pairs of tracings were recorded, together with standard cardiography.

1. Pressures and intracardiac electrogram of the right ventricle.

2. Pressures and intracardiac electrogram of the left ventricle.

3. Pressures of the right and left ventricles.

4. Intracardiac electrogram of the right and left ventricles.

The thorax was opened by means of a large incision at the fourth intercostal space, the parietal pleura was incised and opened wide to uncover the pericardial sac, which was opened after its surface had been sprinkled with 1 per cent scurocain solution. To maintain respiration with the thorax open a Magill tube connected to a cylinder containing soda lime was introduced into the trachea and oxygen was pumped in rhythmically by means of an anæsthesia balloon.

To produce the right bundle-branch block, a large suture needle, with its concavity up and to the left, was introduced through the anterior wall of the right ventricle near the intraventricular septum and immediately below the conus of the pulmonary artery. In this way, when the needle was turned a lesion was produced on the right surface of the septum.

Left bundle-branch block was produced by introducing the needle through the anterior wall of the left ventricle and passing the point on to the left face of the septum.

The appearance of bundle-branch block was confirmed in both intracardiac and peripheral leads. (Fig. 1 and 2.) 


\section{RESULTS}

Relationship between the mechanical systoles of the blocked ventricle and its contralateral. Initially isometric systole was observed to begin simultaneously in both ventricles in all cases. After right bundlebranch block, the isometric contraction of the right ventricle began $0.02-0.06 \mathrm{sec}$. after that of the left ventricle (Fig. 3); and similarly, after left bundle-branch block, the isometric contraction of the left ventricle began $0.02-0.05 \mathrm{sec}$. after that of the right ventricle (Fig. 4).
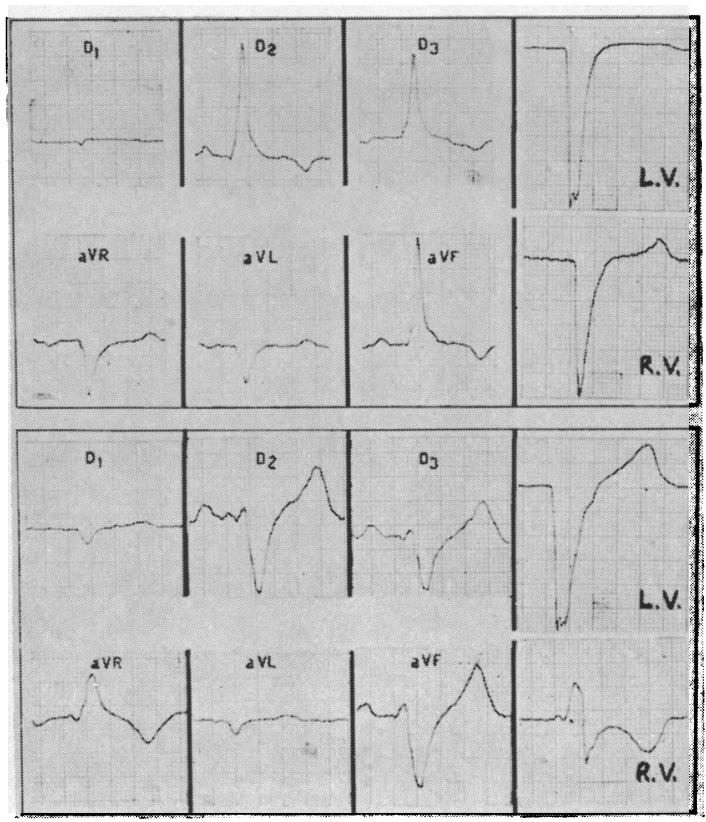

FIg. 1.-Dog. Peripheral and intracardiac leads before (above) and after (below) right bundle-branch block.

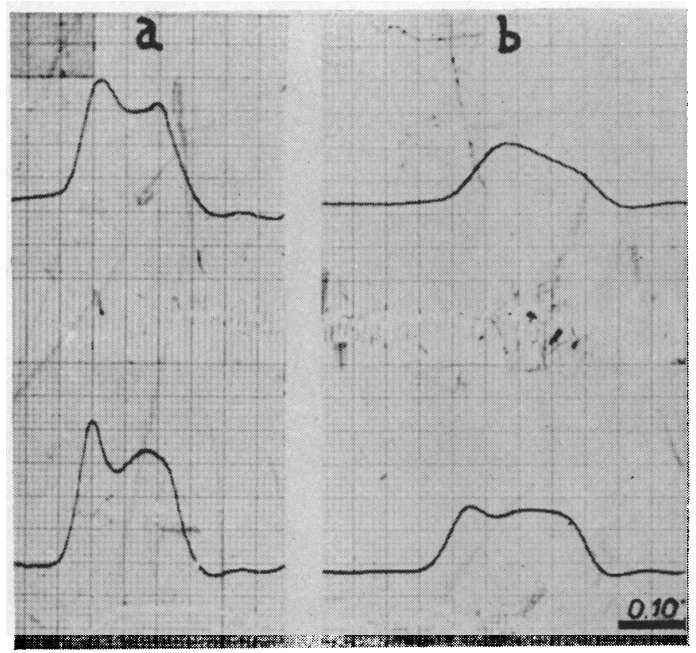

FIG. 3.-Dog. Right (above) and left (below) ventricular pressure curve before (a) and after (b) right bundle-branch block.

2 I
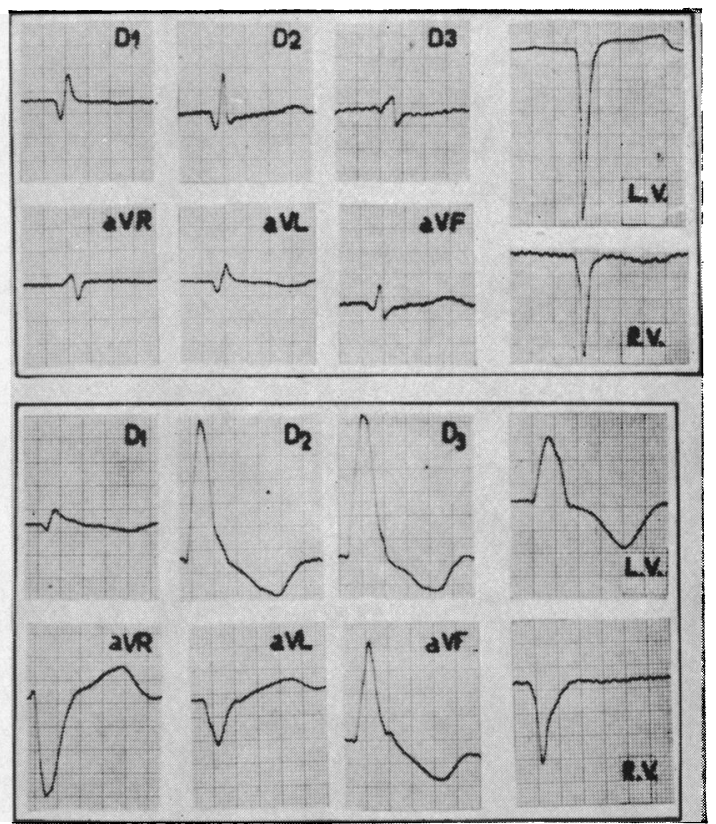

FIG. 2.-Dog. Peripheral and intracardiac leads before (above) and after (below) left bundle-branch block.

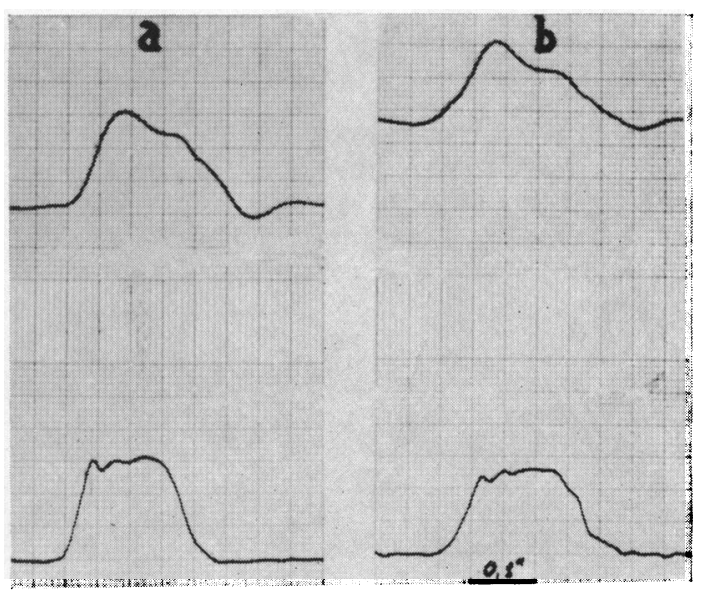

FIG. 4.-Dog. Right (above) and left (below) ventricular pressure curve before (a) and after (b) left bundle-branch block. 
Relationship between electrical and mechanical systole in the blocked ventricle. Initially in both ventricles the delay between electric and mechanical events was 0.04-0.06 sec. After right bundle-branch block, this interval was lengthened in the right ventricle by varying amounts in different experiments, from $0.03-0.06 \mathrm{sec}$. (the increase was $0.02 \mathrm{sec}$. in two cases) so that mechanical systole began $0.08-0.12 \mathrm{sec}$. after the beginning of electrical systole (Fig. 5). After left bundle-branch block, the same interval increased by $0.03-0.04 \mathrm{sec}$. (in one case there was no increase), this making the delay between electrical and mechanical systole 0.07-0.09 sec. (Fig. 6).

Relationship between electrical and mechanical systole in the contralateral ventricle. In all but three of our experiments no change in the relationship between mechanical and electrical systole in the contralateral ventricle was found after section of a branch of the bundle of His (Fig. 7, 8). In one right bundle-branch block and one left bundle-branch block an increase in delay of $0.01 \mathrm{sec}$. was observed, and in a third case the increase was $0.02 \mathrm{sec}$.

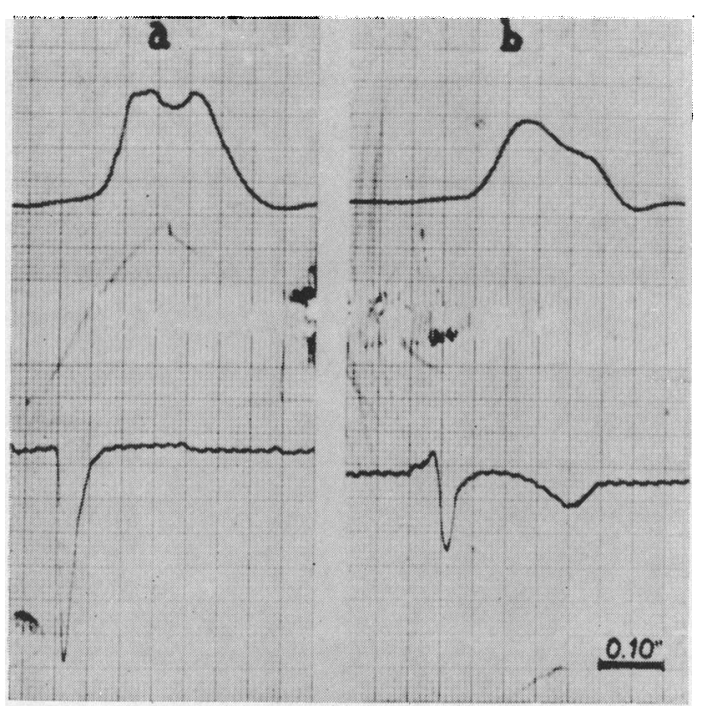

FIG. 5.-Dog. Right ventricular pressure curve (above), right ventricular intracavitary electrogram (below) before (a) and after (b) right bundle-branch block.

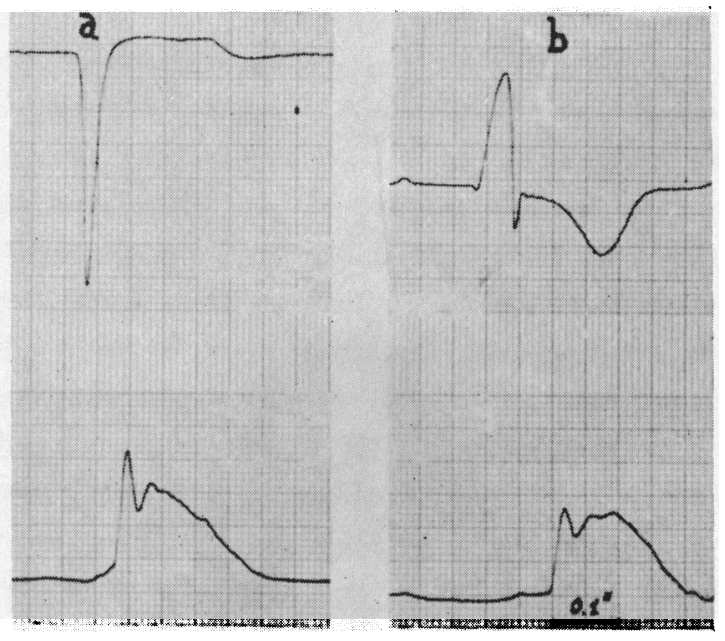

FIG. 6.-Dog. Left ventricular intracavitary electrogram (above), left ventricular pressure curve (below) before (a) and after (b) left bundle-branch block.

Morphology of the rapid complex in the cavity of the left ventricle. Initially a QS complex was always recorded from the cavity of the left ventricle (Fig. 1, 2, 6, 7, 9, 10). After right bundle-branch block, notching or thickening of this negative complex was observed (Fig. 1, 7, 10). After left bundle-branch block a small $Q$ wave remained in 11 cases (Fig. 2,6). In all cases a large $R$ wave followed by an $S$ wave of varying depth appeared (Fig. 2,6,9). In several cases the intracardiac electrode was moved inside the ventricle, producing modifications in the form of the rapid complex and variations in the relationship between the $\mathbf{R}$ and $\mathbf{S}$ waves (Fig. 9).

Morphology of the rapid complex in the cavity of the right ventricle. Initially in the right ventricular cavity the rapid complex generally consists of a QS wave (Fig. 1, 2, 5, 8, 9, 10); in 6 cases an rS complex was recorded; in 2 cases both a QS and an $\mathrm{rS}$ complex were recorded successively.

After right bundle-branch block, a large $\mathrm{R}$ wave appeared (Fig. 1, 5, 10); an RS complex was recorded in 6 cases, Rs in 1, qRS in 6, rsR' $S^{\prime}$ in $4, r R^{\prime} S$ in $1, r R^{\prime} s$ in $2, R$ in 1 . Very often two or more of these patterns appeared in succession, and variations in the relationship between the $R$ and $S$ waves were frequently observed.

After left bundle-branch block the form of the rapid complex in the right ventricular cavity was unchanged (Fig. 2, 8, 9); of the two cases in which an $\mathrm{rS}$ complex was recorded initially, one remained unchanged and a QS wave appeared in the other. 


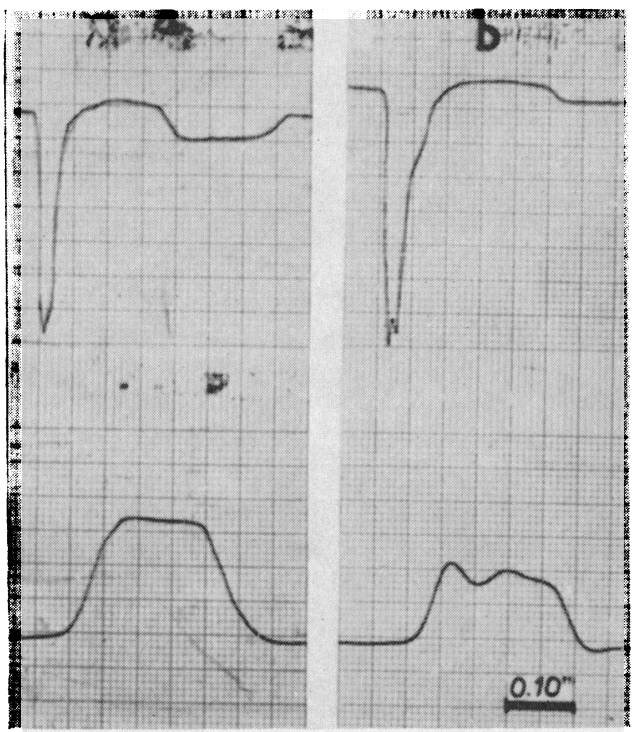

FIG. 7.-Dog. Left ventricular intracavitary electrogram (above), left ventricular pressure curve (below) before (a) and after (b) right bundle-branch block.

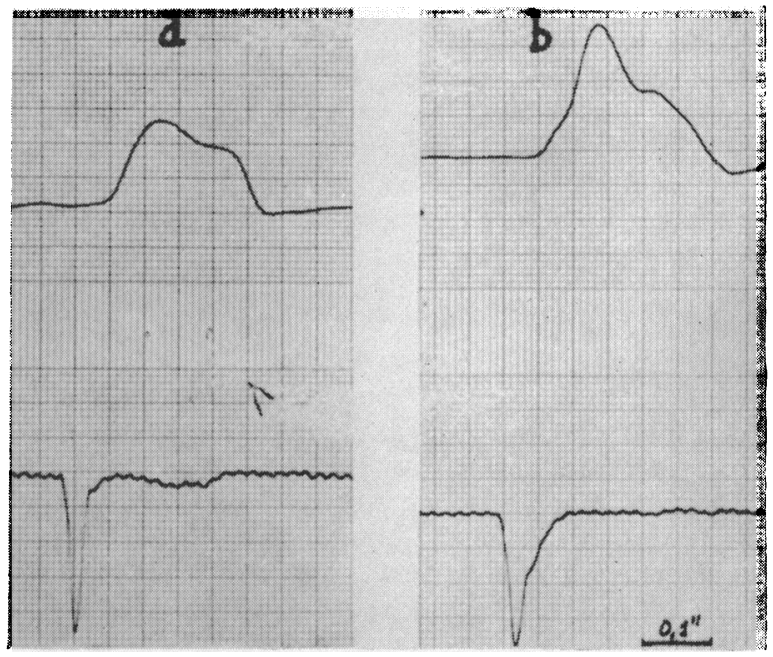

FIG. 8.-Dog. Right ventricular pressure curve (above), right ventricular intracavitary electrogram (below) before (a) and after (b) left bundle-branch block.

Morphology of the $T$ wave in the cavity of the left ventricle. Initially the $T$ wave was positive in 24 cases and negative in 9 (Fig. 1, 2, 6, 7, 9, 10). After right bundle-branch block it remained positive in 8 out of 10 cases, became positive in 7 out of 9 cases formerly negative; a negative $T$ wave was observed in 3 cases, in 2 of which it was formerly positive (Fig. 1,7,10). After left bundle-branch block the $T$ wave became negative in all cases; in those where it had been negative in basal conditions it became more negative (Fig. 2, 6, 9).

Morphology of the $T$ wave in the cavity of the right ventricle. Initially the $T$ wave was positive in 26 cases, and negative in the other 7 (Fig. 1, 2, 5, 8, 9, 10). After right bundle-branch block the $T$ wave became negative in all cases (Fig. 1, 5, 10); in those where it had been negative in basal conditions it became more negative (Fig. 2, 8, 9). Conversely, after left bundle-branch block, the $\mathrm{T}$ wave became positive in all cases; where it had been positive initially it became more positive.

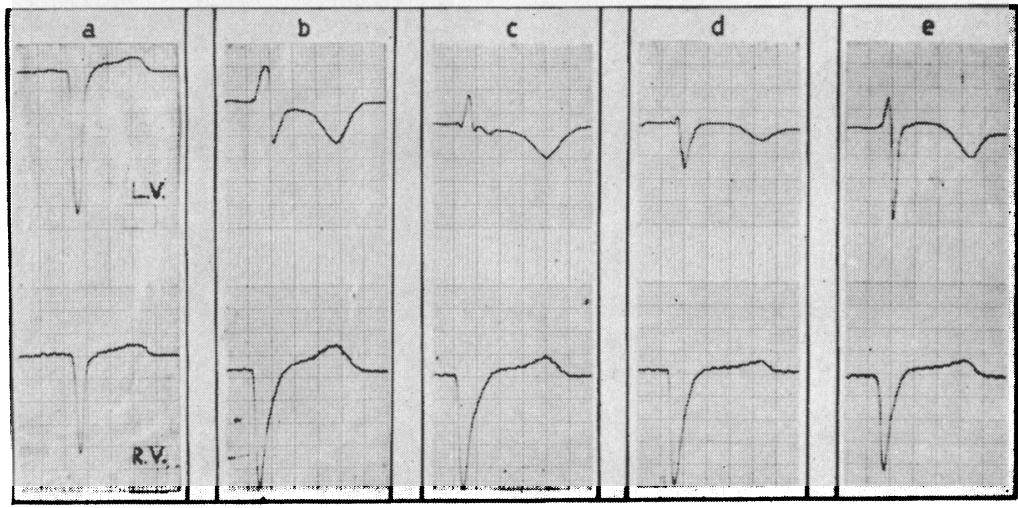

FIG. 9.-Dog N.76 b. Left (above) and right (below) ventricular electrogram in basal conditions (a) and after left bundle-branch block, while moving the left intracardiac electrode $(b, c, d, e)$. 
Intrinsic deflection in the cavity of the left ventricle. Initially the interval between the beginning of the rapid complex and the peak of the $S$ wave was 0.01-0.03 sec. (Fig. 1, 2, 6, 7, 9, 10). After right bundlebranch block there was no change in 12 cases, and a slight increase compared with the initial values in 6 $(0.005 \mathrm{sec}$. in 5 cases, $0.001 \mathrm{sec}$. in 1) (Fig. 1, 7, 10). After left bundle-branch block the end of the intrinsic deflection was recorded $0.05-0.08 \mathrm{sec}$. after the beginning of the rapid complex: thus it was delayed, compared with the initial values, by $0.02-0.065$ sec. (Fig. 2, 6, 9).

Intrinsic deflection in the cavity of the right ventricle. Initially the interval between the beginning of the rapid complex and the end of the intrinsic deflection was 0.01-0.025 sec. (Fig. 1, 2, 5, 8, 9, 10). After right bundle-branch block the end of the intrinsic deflection was recorded 0.04-0.09 sec. after the beginning of the rapid complex; thus the interval was increased by $0.03-0.065 \mathrm{sec}$. compared with the initial values (Fig. 1, 5, 10). After left bundle-branch block there were slight changes in the interval between the beginning of the rapid complex and the end of the intrinsic deflection in only 3 cases, an increase of $0.005 \mathrm{sec}$. in 2 cases and 0.015 sec. in 1 (Fig. 2, 8, 9).

Duration of the rapid complex in the right and left intracardiac leads. Neither before nor after right or left bundle-branch block was there any difference between the duration of the rapid ventricular complex recorded from the left and right ventricles. The duration was $0.03-0.06 \mathrm{sec}$. before and $0.08-0.11 \mathrm{sec}$. after right bundle-branch block, so that there was an increase of $0.02-0.05 \mathrm{sec}$. compared with the initial values; after left bundle-branch block, the duration of the rapid ventricular complex was $0.06-0.10$ sec., an increase of 0.01-0.05 sec. compared with the initial values (Fig. 1, 2, 5, 6, 7, 8, 9, 10).

On two hearts in which we had produced left bundle-branch block by means of a lesion of the left septal surface, histological examination clearly demonstrated a lesion interrupting the left branch (Fig. 11). All the fibres of this branch were interrupted in the region of the sub-endocardial septum, but it must be borne in mind that since the branch divides into numerous branches within a few millimetres of its beginning, the section could have been made below the first subdivisions of the branch.

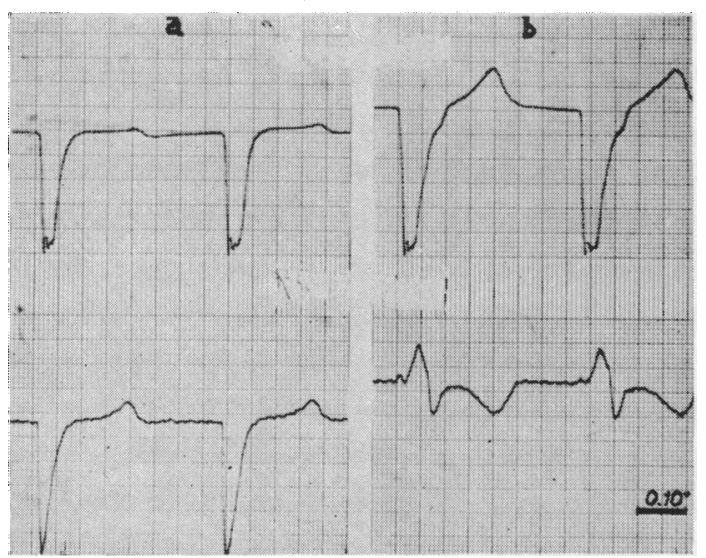

Fig. 10.-Dog. Left (above) and right (below) ventricular intracavitary electrogram before (a) and after (b) right bundle-branch block.

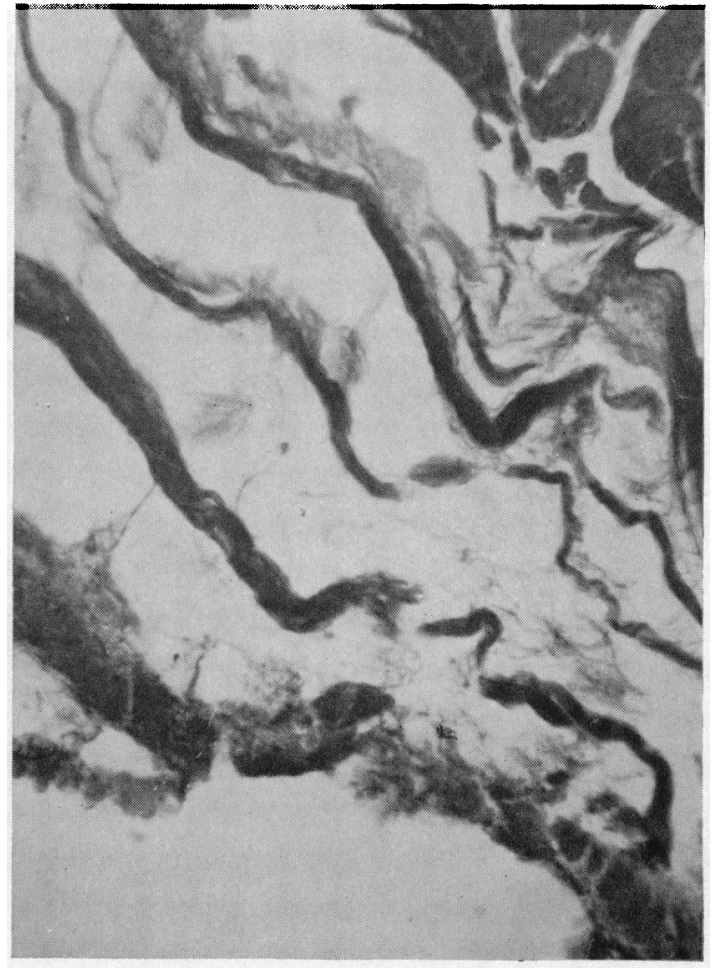

Fig. 11.-Lacerated and sectioned fibres of the left branch of the bundle of His below the left septal endocardiac surface. 


\section{DisCUSSION}

Measurements of the time interval between the beginning of the electrical systole and the beginning of the mechanical systole of each ventricle, and between the mechanical systole of the two ventricles, in normal conditions and after section of one branch of the bundle of His have shown that the mechanical systole of the ventricle whose branch has been cut is delayed, while the relationship between the electrical and mechanical events in the opposite ventricle remains unchanged. The delay in mechanical systole of the blocked ventricle is the same as the delay in the intrinsic deflection of the same ventricle.

Examination of intracardiac electrograms shows that the data we have obtained in normal conditions as to the morphology of the rapid depolarization complex is in agreement with the observations of other authors. In the left ventricle we have always recorded a QS complex. In the right ventricle we have sometimes recorded a QS complex ( 25 cases), sometimes an rS complex ( 6 cases), and in 2 cases both kinds of complex successively. This last finding is confirmation of the fact that in the right ventricle the recording of a completely negative complex or of a complex preceded by a small $R$ wave depends on the position of the electrode in the ventricle.

Our results do not support the view that intracardiac leads record a negative $\mathrm{T}$ wave either in the right or the left ventricle. The $T$ wave was positive 26 times in the right ventricle and 24 times in the left ventricle, whereas it was negative only 7 and 9 times respectively. The possibility that these variations were due to mechanical irritation of the endocardium by the intracardiac electrode can be excluded, as there were no extrasystoles and none of the $S-T$ changes that are the most frequent expression of such irritation. Probably these $T$ changes are due to the changing position of the electrode in the ventricle. In some of our experiments, flat, negative, or positive $T$ waves were produced simply by pushing or pulling the electrode without producing any signs of its touching the ventricular wall.

The time between the beginning of the rapid complex and the end of the intrinsic deflection was $0.010-0.025 \mathrm{sec}$. in the right ventricle, and 0.010-0.030 sec. in the left ventricle. The duration of the intrinsic deflection was $0.010-0.015 \mathrm{sec}$. in both ventricles. In these intracardiac tracings the intrinsic deflection, or better the end of the intrinsic deflection, indicated the moment when the depolarization dipole, having activated the subendocardial layers of the ventricular myocardium, leaves the exploring electrode: if this is placed very close to the ventricular wall it shows in particular the passage of the activating wave in this point (Latour and Puech, 1957).

The morphology of the complex after section of the right and left branch of the bundle of His shows constant and characteristic changes.

A large $R$ wave appears in the cavity of the blocked ventricle, while the $S$ wave is significantly reduced in amplitude. Kennamer and Prinzmetal (1954) affirmed that complete bundle-branch block causes the disappearance or great reduction of the $S$ wave, and that a fairly deep $S$ wave would remain only where the block was incomplete. Our findings do not agree with these observations: even where the increased duration of the rapid complex, the morphology of the tracings in the peripheral leads, and the marked delay of the intrinsic deflection demonstrated complete block, a deep $S$ wave was recorded in the blocked wave (RS, Rs, rR'S, RR'S, rsR'S' were all observed). Sodi-Pallares et al. (1955) have also recently obtained results that, in agreement with ours, fail to confirm Kennamer and Prinzmetal's conclusions and suggest that in the blocked ventricle, the details of the morphology of the rapid complex can vary with the position of the electrode. We too were able to support this view, as several times in the course of the same experiment we produced changes in the shape of the rapid complex by moving the intracardiac electrode, avoiding contact between the electrode and the endocardium.

According to Kennamer and Prinzmetal (1954) the $R$ wave recorded in the cavity of the blocked ventricle is later than the $R$ recorded in the external layers of the wall and of the epicardiac surface, and therefore cannot be considered to be transmitted from the ventricular cavity, nor as originating in the depolarization of the septum. Since this is not possible to determine directly from the time of appearance of the intramural or epicardial $\mathbf{R}$ wave, it seems to us that it cannot be considered 
delayed as it can be recorded immediately the impulse arrives at the left septal surface, that is from the inception of ventricular depolarization: thus this wave begins at the same moment as the electrode in the contralateral ventricular cavity records the appearance of the $Q$ wave (Fig. 9, b, c; 10).

The left intraventricular tracing after section of the left branch of the bundle of His showed that in 11 cases out of 15 the rapid complex began with a small q wave. The persistence of a $q$ wave in the left ventricular cavity even after left bundle-branch block-a phenomenon that had not been observed before-indicates the persistence of a left-to-right activation current of the septum. The left branch of the bundle of His, unlike the right, remains undivided only for a very short distance and then divides into numerous branches, and the persistence of the small $\mathrm{q}$ wave is probably due to incomplete section, one or more of the branches that leads from the left branch of the bundle of His to the intraventricular septum having been left intact.

In the right intracardiac electrographic tracings after section of the corresponding branch of the bundle of His, the initial large $R$ wave indicates activation of the septum from left to right, and of a part of the musculature of the left ventricle. The end of the intrinsic deflection indicates the moment when the stimulus, which has reached the right surface of the septum below the block by abnormal pathways, causes depolarization of the right ventricular wall. In the left intracardiac electrographic tracings after bundle-branch block the small $\mathrm{q}$ wave indicates activation from left to right of a zone in the septum; the $\mathrm{R}$ wave corresponds to activation from right to left of the remaining portion of the septum, and of a part of the right ventricle. The end of the intrinsic deflection coincides with the arrival of the stimulus at the left surface of the septum and thus with the depolarization of the muscular wall of the left ventricle.

After bundle-branch block there is always an increase in the interval between the beginning of the rapid complex and the end of the intrinsic deflection: this is due to the delay suffered by the activating wave in reaching the blocked ventricle. Kennamer and Prinzmetal (1954) have stated that the impulse not only arrives late at the resected part of the bundle of His, but also follows abnormal pathways in spreading to the wall of the blocked ventricle. In opposition to this, SodiPallares et al. (1955) have stated that the stimulus, which has reached the Purkinje network of the septum by abnormal pathways below the interruption in the branch, then spreads normally in the wall of the corresponding ventricle. These authors were led to this conclusion by their observations that the speed and direction of the exciting wave, studied at neighbouring points of the ventricular myocardium by means of differential bipolar leads, remain unchanged after section of a branch of the bundle of His. Our results, although they do not permit us to recognize the direction followed by the stimulus in the thickness of the ventricular wall, are in agreement with the hypothesis of Sodi-Pallares et al. rather than with that of Kennamer and Prinzmetal. In effect, the changes in the rapid complex in the cavity of the blocked ventricle are restricted to the part of it that precedes the intrinsic deflection and therefore reflects the activation of the contralateral ventricle. The second part of the intraventricular complex, corresponding to the activation of the myocardium of the blocked ventricle, remains normal.

The $\mathrm{T}$ wave too, after right or left branch block, undergoes constant and characteristic changes. Section of a branch of the bundle of His causes inversion or accentuation of the negativity of the $\mathrm{T}$ wave in the corresponding ventricle. The inversion of the $\mathrm{T}$ wave in the course of branch block has already been reported; it corresponds to modification of the process of repolarization. However, we have not found any clear description of the behaviour of the $T$ wave in the unaffected ventricle. Here, in most cases ( 30 out of 35 ), the $\mathrm{T}$ wave becomes positive, and taller if it was already positive in normal conditions. As it is believed that section of a branch of the bundle of His does not cause changes in the depolarization of the contralateral ventricle, we do not believe that the alterations in the $T$ wave can be attributed to modifications in the repolarization of this ventricle. It is probable, on the contrary, that the characteristic behaviour of the $T$ wave in the two ventricles is related to the direction of the repolarization of the septum; according to SodiPallares et al. (1955) this is from left to right after right bundle-branch block, and from right to left after left bundle-branch block. 


\section{SUMMARY AND CONCLUSIONS}

In order to examine the influence of bundle-branch block on mechanical systole and the intracavitary electrogram, we recorded the ventricular pressure curves and the intracavitary electrogram of both ventricles before and after section of the right and left branches of the bundle of His in the dog.

In the blocked ventricle the delay between electrical and mechanical events increases, and the mechanical systole is delayed: this delay corresponds to the delay in the intrinsic deflection of the same ventricle. The delay between electrical and mechanical events in the opposite ventricle is unchanged.

In normal conditions we have always recorded a QS complex or else an $\mathrm{rS}$ complex in the left ventricle according to the position of the electrode in the ventricular cavity. The $T$ wave in both ventricles is generally positive, though occasionally negative: this variation too is probably related to the position of the intracavitary electrode.

After section of the right bundle of His a large $R$ wave is recorded in the blocked ventricle; its relation to the $S$ wave does not vary with the degree of the block but with the position of the intracavitary electrode. After section of the left branch a small $\mathrm{q}$ wave is often recorded in the left ventricular cavity. This records the activation of part of the septum from left to right, probably by some offshoot of the left branch which has remained intact above the point of section.

The $\mathbf{R}$ wave recorded in the cavity of the blocked ventricle is not delayed, but begins simultaneously with the beginning of ventricular depolarization.

In the blocked ventricle the end of the intrinsic deflection is delayed, while the section between the lowest point of the $S$ wave and the end of the complex remains normal. This shows that the spread of the stimulus is impaired until it reaches the blocked ventricle, whereas the subsequent process of ventricular depolarization remains unchanged.

In accordance with the changes in the repolarization of the blocked ventricle the $T$ wave in the corresponding intracavitary tracing becomes negative. In the opposite ventricle the $T$ wave becomes positive or more positive.

We wish to thank Dr. Wallace Brigden for his helpful criticism.

\section{REFERENCES}

Alzamora-Castro, V., Abugattas, R., Rubio, C., Bouroncle, J., Zapata, C., Santa-Maria, E., Battilana, G., Binder, T., Subiria, R., and Paredes, D. (1953). Circulation, 7, 108.

Braun-Menendez, E., and Solari, L. A. (1939). Arch. intern. Med., 63, 830.

Braunwald, E., Donoso, E., Sapin, S. O., and Grishman, A. (1956). Circulation, 13, 866.

- and Morrow, A. G. (1957). Amer. J. Med., 23, 205.

Chamberlein, W. E., Boone, B. R., Ellinger, G. F., Henny, G. C., and Oppenheimer, M. J. (1947). Fed. Proc. Soc. exp. Med., 6, 88.

Coblentz, B., Harvey, R. M., Ferrer, M. I., Cournand, A., and Richards, D. W. (1949). Brit. Heart. J., 11, 1.

Donoso, E., Sapin, S. O., Braunwald, E., and Grishman, A. (1955). Amer. Heart J., 50, 674.

Ellinger, G. F., Gillick, F. G., Boone, B. R., and Chamberlein, W. E. (1948). Amer. Heart J., 35, 971.

Eppinger, H., and Rothberger, C. J. (1911). Zentralbl. Physiol., 24, 1055.

Gigli, G., and Muiesan, G. (1956). Rif. Med., 70, 1429.

Gray, I. R. (1956). Brit. Heart J., 18, 21.

Groedel, F. M. (1944). Exper. Med. Surg., 2, 352.

Katz, L. N. (1925). Amer. J. Physiol., 72, 218.

$\longrightarrow$, Landt, H., and Bohning, A. (1935). Amer. Heart J., 10, 681.

Kennamer, R., and Prinzmetal, M. (1954). Amer. Heart J., 47, 769.

Lasser, R. P., Borun, E. R., and Grishman, A. (1951).. Amer. Heart J., 41, 667.

Latour, A., and Puech, P. (1957). Electrocardiographie endocavitaire. Masson \& C. Ed., Paris.

Richards, B., Harvey, R. M., Ferrer, M. I., Cournand, A., and Richards, D. W. (1947). Trans. Ass. Amer., Physc. 60, 65.

Samet, P., Mednick, H., and Schwedel, J. B. (1950). Amer. Heart J., 39, 841.

Segers, M. (1949). Amer. Heart J., 37, 92.

, and Hendrick, J. (1951). Acta. Cardiol., 6, 1950.

Sodi-Pallares, D., Bisteni, A., Medrano, G. A., and Cisneros, F. (1955). Amer. Heart J., 49, 587.

, Estandia, A., Soberon, J., and Rodriguez, M. I. (1950). Amer. Heart J., 40, 655. 